\title{
Simulated spinal cerebrospinal fluid leak repair: an educational model with didactic and technical components.
}

\author{
George M. Ghobrial, MD \\ Thomas Jefferson University \\ Paul A Anderson \\ University of Wisconsin, Madison, WI \\ Rohan Chitale, MD \\ Thomas Jefferson University \\ Peter Campbell, MD \\ Thomas Jefferson University \\ Parlewhen aRdelddAtPonal works at: https://jdc.jefferson.edu/neurosurgeryfp \\ Thomas Jefferson University \\ Part of the Medicine and Health Sciences Commons

\section{Let us know how access to this document benefits you} \\ See next page for additional authors
}

\section{Recommended Citation}

Ghobrial, MD, George M.; Anderson, Paul A; Chitale, MD, Rohan; Campbell, MD, Peter; Lobel, MD, Darlene A; and Harrop, MD, James, "Simulated spinal cerebrospinal fluid leak repair: an educational model with didactic and technical components." (2013). Department of

Neurosurgery Faculty Papers. Paper 50.

https://jdc.jefferson.edu/neurosurgeryfp/50

This Article is brought to you for free and open access by the Jefferson Digital Commons. The Jefferson Digital Commons is a service of Thomas Jefferson University's Center for Teaching and Learning (CTL). The Commons is a showcase for Jefferson books and journals, peer-reviewed scholarly publications, unique historical collections from the University archives, and teaching tools. The Jefferson Digital Commons allows researchers and interested readers anywhere in the world to learn about and keep up to date with Jefferson scholarship. This article has been accepted for inclusion in Department of Neurosurgery Faculty Papers by an authorized administrator of the Jefferson Digital Commons. For more information, please contact: JeffersonDigitalCommons@jefferson.edu. 


\section{Authors}

George M. Ghobrial, MD; Paul A Anderson; Rohan Chitale, MD; Peter Campbell, MD; Darlene A Lobel, MD; and James Harrop, MD 


\title{
As submitted to:
}

Neurosurgery

And later published as:

Simulated Spinal Cerebrospinal Fluid Leak Repair: an Educational

Model with Didactic and Technical Components

Volume 73, October 23, 2013, Supplement 1, pages: 111-115.

DOI: 10.1227/NEU.0000000000000100.

\author{
George M. Ghobrial, MD \\ Paul A. Anderson, $M D^{b}$ \\ Rohan Chitale, $\mathrm{MD}^{\mathrm{a}}$ \\ Peter G. Campbell, MD ${ }^{\mathrm{a}}$ \\ Darlene A. Lobel, $\mathrm{MD}^{\mathrm{c}}$ \\ James Harrop, $\mathrm{MD}^{\mathrm{a}}$
}

Disclosures/Acknowledgements: None

${ }^{a}$ Department of Neurosurgery, Thomas Jefferson University Hospital, Philadelphia, PA, USA

${ }^{b}$ Department of Orthopedics, University of Wisconsin, Madison, WI, USA

${ }^{c}$ Department of Neurologic Surgery, Mayo Clinic, Rochester, MN, USA

Disclosures/Financial Support: None.

Corresponding author:

James Harrop, MD

Department of Neurosurgery 
Thomas Jefferson University

909 Walnut, $3^{\text {rd }}$ Floor

Philadelphia, PA 19107

Phone: 215-955-7000Fax: 215-503-9170

james.harrop@jefferson.edu

\section{$\underline{\text { Abstract }}$}

Background: In the era of surgical resident work hour restrictions, the traditional apprenticeship model may provide fewer hours for neurosurgical residents to hone technical skills. Spinal dura mater closure or repair is one skill that is infrequently encountered and persistent cerebrospinal fluid leaks are a potential morbidity.

Objective: To establish an educational curriculum to train residents in spinal dura mater closure with a novel durotomy repair model.

Methods: The Congress of Neurosurgeons (CNS) has developed a simulation based model for durotomy closure with the ongoing efforts of their simulation educational committee. The core curriculum consists of didactic training materials and a technical simulation model of dural repair for the lumbar spine.

Results: Didactic pre-test scores ranged from 4/11 (36\%) to 10/11 (91\%). Post-test scores ranged from $8 / 11(73 \%)$ to $11 / 11(100 \%)$, Overall, didactic improvements were demonstrated by all participants, with a mean improvement between pre-and post-test scores of 1.17(18.5\%), $(\mathrm{p}=0.02)$. The technical component consisted of eleven durotomy closures by six participants, where four participants performed multiple durotomies. Mean time to closure of the durotomy ranged from 490 to 546 seconds in the first and second closures, respectively $(\mathrm{P}=0.66)$, whereby the median leak rate improved from 14 to $7(\mathrm{P}=0.34)$. There were also demonstrative technical improvements by all. 
Conclusion: Simulated spinal dura mater repair appears to be a potentially valuable tool in the education of neurosurgery residents. The combination of a didactic and technical assessment appears to be synergistic in terms of educational development.

Key Words: Durotomy, Resident Training, CSF Repair, Neurosurgery simulation.

Short Title: Cerebrospinal Fluid Leak Simulator Didactic 


\section{Introduction}

The Congress of Neurosurgeons (CNS) global mission is to enhance health and improve lives worldwide through the advancement of education and scientific exchange. One powerful method to accomplish this mission is to improve the quality and efficiency of neurosurgical resident education. Due to several factors, the present traditional apprenticeship educational model provides fewer hours for neurosurgical residents training than when this model was first established. Proficiency of technical skills has been shown to be quantity related, where increased exposure results in improved skills. ${ }^{1,2}$ Spinal dura mater breaches with resultant cerebrospinal fluid leaks are a recognized complication in spinal surgery. Dural repair and closure requires considerable familiarity with dural anatomy, tissue consistency and fine surgical technique in a closed space to achieve technical effectiveness. With fewer hours of real time operative training, obtaining excellence in adequate, timely, and watertight primary dural closure will be at a significant risk.

Technical simulators are increasingly being used to provide training for specific skills when opportunities to learn those skills are not otherwise readily available. A theoretical advantage to increasing skill set experiences with a technical simulator is that there is a potential decreased exposure risk to the patient, since technical components should be at a higher level when implemented. This is especially advantageous for durotomy repair, as the technical components are unique in spinal surgery, and there is risk for persistant CSF leak and pseudomeningocoele with improper dural closure. Furthermore, given the risks of nerve root or spinal cord injury from dural repair are present, resident participation in CSF leak closure is historically low.

Significant advances in the methodology of teaching and training medically-based procedures through the use of simulation devices has gained widespread acceptance in many 
surgical or procedural based practices. ${ }^{3-7}$ However, in neurological surgery there are relatively few simulator models that are available. The CNS simulation committee therefore designed and integrated several spine simulation modules as a component of the neurosurgical simulation curriculum. In order to enhance and maximize this educational experience, each simulator was developed to specifically meet curricular goals. The simulators were introduced as part of a twohour module incorporating both didactic and technical training components.

This manuscript details one of these models, the CSF leak/ spinal dura mater repair educational model. Spinal dural repair through suturing in the setting of a spinal dural laceration is a technically demanding surgical skill. Through repetitive use of a physical simulation model of open spinal dural repair, the authors proposed to objectively measure the ability of neurosurgical residents and gauge their level of improvement with this skill set. The goal of our model is to demonstrate improved proficiency of the residents in performing dural closure within the confinements of exposure typically seen in the operative setting. Attaining a fundamental skill set using such a simulator may help simultaneously improve technical skills of trainees and operative outcomes.

\section{METHODS}

The dural repair module was developed to educate residents in techniques to improve speed and quality of dural closure. The framework of this educational model included didactic and practical, simulator based components. The course participants completed an 11-question written pre-test, to assess current knowledge of relevant spinal anatomy, knowledge of CSF 
repair techniques, and complications associated with inadequate dural closure. Questions were vetted through the spine sub-committee of the CNS Simulation Committee. Residents then completed a detailed didactic educational curriculum reviewing and enforcing these concepts. Technical skills of participants were then assessed with a spinal CSF leak repair simulator. This model was adapted and modified from a physical simulation model previously validated and described elsewhere in the literature by one senior author (PA). ${ }^{8}$ Specifically, a sawbone reproduction of the lumbar spine from L1 to sacrum was obtained and a L3 laminectomy performed(Sawbones Worldwide, Vashon Island, WA). Numerous synthetic materials were tested in order to obtain a tissue consistency similar to spinal dura mater. A dural substitute (DURA-GUARD, Synovis, Surgical, St. Paul, MN) was identified that closely mimicked the textural properties of native dura. This was then individually manually fashioned into a watertight tube and placed within the spinal canal to serve as a thecal sac. Both proximal and distal ends of the simulated thecal sac were occluded by an inflated 14 French foley catheter balloon (Figure 1). The caudal foley catheter was clamped while the proximal foley catheter was connected to an elevated one liter bag of normal saline with an intervening drip chamber and clamp. Unclamping the proximal clamp allowed the saline reservoir to fill the thecal sac, thus creating a closed system with a pressure gradient dependent upon the height of the saline reservoir, which was adjustable.

The flow rate of saline into the closed simulated thecal sac system was calculated by determining the number of drops per minute of saline from the reservoir into the drip chamber. Baseline leak rates were identified with the reservoir set at a pressure of $20 \mathrm{cc}$ of water to mimic normal cerebrospinal fluid pressure. This was done to standardize the pressure of fluid across 
the closure repair, and the pressure can be increased or decreased to test the quality of the dural closure.

With baseline system measurements recorded, a longitudinal dural incision $1.5 \mathrm{~cm}$ was created within the site of the L3 laminectomy bed in the center of the thecal sac (Figure 2). This altered the pressure gradient and increased the CSF flow and amount of fluid released. The participant then using 6-0 gortex suture to perform a running dural closure (Figure 3). This performance was measured and graded on two criteria: speed of closure, and quality of closure. Speed of closure was measured by recording the time in seconds from initiation of first suture to completion of closure with securing the final knot. Quality of the closure was assessed by measuring the difference in the post-closure saline chamber drip rate compared to the baseline drip rate. Achieving a post-closure drip rate equal to the baseline drip rate represents a watertight closure at a pressure of $20 \mathrm{cc}$ of water (Figure 4).

For the technical component of the durotomy repair on the simulator, participants attempted the dural closure of the standard length $(1.5 \mathrm{~cm})$ without a time restriction (See supplemental video 1). Throughout the technical component instructors aided the participants with surgical technique and again re-inforced basic concepts of neurosurgical anatomy and pathophysiology.

Statistical analysis of pre-didactic and post-didactic scores as well as improvement on subsequent durotomy closures was analyzed via a software package (JMP statistical software, edition 8.0.1, www.jmp.com) with the matched pairs method. Statistical significance was defined by the authors as having an alpha value of less than 0.05 ..

\section{Results}


The spinal dural CSF leak repair educational module was utilized at the 2012 CNS simulation course held in the Chicago convention center at the CNS annual meeting. Six participants were included in the analysis, including four neurosurgery residents: PGY2, PGY3, PGY4, and PGY5, one retired neurosurgeon (>10 years retirement), and one physician assistant without prior dural closure experience. All of the neurosurgeons were male (5 out of 6 ). There was one American resident and one physician assistant practicing in the U.S., while the rest were international participants.

In the didactic portion of the educational module, the pre-test scores ranged from $4 / 11$ (36\%) to 10/11 (91\%). Overall, improvement was demonstrated by all applicants (table 1) with post-test scores ranging from $8 / 11(73 \%)$ to $11 / 11(100 \%)$. The mean pre-test didactic scores were 6.33 and the mean post-test didactic score was 7.50 with a mean improvement of $1.17(18.5$ $\%, \mathrm{p}=0.02$ ). Two participants demonstrated the greatest change from pre-test to post-test written scores, improving from 4 to 10/11(150\%) and 6 to 9/11(50\%). One applicant failed to complete the module due to time constraints and did not take the post-test.

In the technical portion of the module, there were eleven durotomy closures for the six participants with timing of the repairs ranging from 4 minutes 14 seconds to 15 minutes (table 2). Four participants performed more than one attempt at durotomy closure. For the applicants who completed multiple closures, there was improvement observed with repeated attempts. The leak rate change, calculated by the difference between drip rate from reservoir with the dura intact and after the repair was completed, measured the fidelity of the dural closure. Results ranged from 5 to 70 drips (in the fluid column) per thirty seconds. Improvement among the neurosurgery residents was evident. Mean time to closure of the durotomy ranged from 490 to 546 seconds in the first and second closures, respectively $(\mathrm{P}=0.66)$, whereby the median leak rate 
improved from 14 to $7(\mathrm{P}=0.34)$. There were also demonstrative technical improvements by all.

\section{Discussion}

Neurosurgeons encounter spinal dural breaches not infrequently during spinal surgery. Etiologies range from traumatic injuries as seen after burst fractures, to congenital dural defects or arachnoid cysts as well as iatrogenic dural openings. The rate of incidental spinal durotomy varies in the literature. ${ }^{9-16}$ Takahashi et al. ${ }^{9}$ reported $4 \%$ of lumbar spinal cases had dural defects in 1014 cases. However, with revision lumbar surgery the reported rates are even higher with incidences noted between 13-15.9\%. ${ }^{13,17,18}$

Performance of surgical procedures requires a detailed understanding of the anatomy along with proper technical skills. The dural repair educational module is a novel way to illustrate important didactic concepts to the participants, as all participants improved in scores of didactic tests. In addition to the didactic components this module also illustrated that, in a very short period of time, quantitative improvements in the fidelity and speed of the durotomy repair can also occur. This was shown by the decrease in the time to complete the set length durotomy closure from a mean of 490 to 456 seconds ( $\mathrm{P}=0.66)$, as well as the decrease in the drip or leak rate nearly back to the baseline scores. Furthermore, this model was very concise and efficient in terms of hours required for training. Other benefits of this model include its portability and potential to be used at any time by the resident as its use does not require supervision by an attending. 
In general, applicants reported perceived increase in ease of closure with time spent on the model, for which a trend can be seen. This was not the case with one applicant, who reported no prior exposure at all to dural closure. While statistically significant improvement was not achieved in the technical evaluation of the spinal fluid repair model, this may have been due to the limited time allotted for this simulation at the CNS Conference, as well as a limitation in the supply of materials available. Further attempts to validate the efficacy of this simulator in improving surgical skills will be internally among residents in a single institution neurosurgery program, as well as across multiple centers. It is likely that the results did not show statistical improvements in the time to durotomy closure because of the variability in the participant skill and the small sample size. The bias introduced by having few participants of varying abilities can be overcome by stratifying performance by resident training level and performing a subgroup analysis in this manner. Another consideration is the duration of time to closure of the durotomy showed an increase in several cases. This could be best explained by the shift in the residents attention from speed to accuracy, upon noting the shortcomings in their durotomy closure, which was evidenced by the improved leak rate.

The chief limitation for implementing this model is the cost of the dural substitute, which is the main component that must be replaced after use, and has a short shelf-life. Other drawbacks include that the dural substitute in use is not identical in character to the dura mater in vivo. However, among a variety of substitutes tested, the 'Dura-Guard' was felt to provide the most realistic tactile feedback for suturing and handling with instruments. The foley catheters are readily available and provide an adequate seal for the fluid in the dural tube, but this results in a continual baseline leak rate. After a durotomy is made, the pressure to the system drops precipitously, until a dural closure is made. Once the closure is made, the fluid fills the tube and 
attempt to equilibrate based on the pressure of the height of the saline bag. The lack of steady pulsatile fluid loss and quick loss of fluid pressure do not adequately mimic CSF dynamics in vivo. As the model is improved the next step would be to make the fluid circuit a truly closed one, such that the system could be completely clamped at the rostral and caudal ends without a fluid leak.

Other improvements to the model may significantly enhance the experience. The sawbones model (Figure 1) does not simulate the often narrow corridor that is encounter by deep wounds caused by obesity, or the paraspinal musculature and soft tissues of the spine. Also, adding to the difficulty and frustration of durotomy closures are blood products that flood the field making continuous visualization of the durotomy tedious. Addition of nerve roots to simulate their proximity to the closure is another possibility to increase the realism that adds to the risk of the repair. Further training models should be included in the future that simulates dural closure in a tubular retractor or a simulated narrow operating corridor. Finally, formalization of the evaluation process for the technical portion of the course may improve the ability to obtain validation data for the model. All course participants should complete a pretraining assessment of dural closure time and post-closure drip rate, followed by a defined period of guided simulator practice, to be followed by a post-training assessment of speed and quality of dural closure. This may require extension of the module to longer than the currently allotted 2 hours in order to provide ample time for these assessments and training period.

\section{Conclusion}


Repair of spinal dura mater is a valuable tool in the education of neurosurgery residents to decrease CSF leak rate and improve speed of closure. The implementation of a didactic program in tandem with a technical simulator has the potential to be beneficial in resident education. 
Table 1. Participant Quiz Scores

\begin{tabular}{|l|l|l|l|l|}
\hline Participant & $\begin{array}{l}\text { Post-Graduate } \\
\text { level(y) }\end{array}$ & $\begin{array}{l}\text { Pre-Test Score (n } \\
\text { correct) }\end{array}$ & $\begin{array}{l}\text { Post-Test Score (n } \\
\text { correct) }\end{array}$ & $\begin{array}{l}\text { Test Score } \\
\text { Change } n(\% \\
\text { improvement) }\end{array}$ \\
\hline 1 & 2 & $4 / 11$ & n/a & n/a \\
\hline 2 & 3 & $7 / 11$ & $8 / 11$ & $1(14)$ \\
\hline 3 & 4 & $10 / 11$ & $11 / 11$ & $1(10)$ \\
\hline 4 & n/a(retired) & $7 / 11$ & $9 / 11$ & $2(28.6)$ \\
\hline 5 & n/a (p.a.) & $6 / 11$ & $9 / 11$ & $3(50)$ \\
\hline 6 & 5 & $4 / 11$ & $10 / 11$ & $6(150)$ \\
\hline Mean & - & 6.33 & 7.5 & $1.17(18.5)$ \\
\hline
\end{tabular}

Table 2. Dural Closure Performances

\begin{tabular}{|l|l|l|l|l|l|}
\hline Participant & $\begin{array}{l}\text { Post- } \\
\text { Graduate } \\
\text { level (y) }\end{array}$ & $\begin{array}{l}\text { Closure } \\
\text { Times (s) }\end{array}$ & $\begin{array}{l}\text { first-leak } \\
\text { rate } \\
\text { (drip/30 s) }\end{array}$ & $\begin{array}{l}\text { second-leak } \\
\text { rate } \\
\text { (drip/30 s) }\end{array}$ & $\begin{array}{l}\text { Leak Rate } \\
\text { Change* } \\
\text { (drip/30 s) }\end{array}$ \\
\hline 1 & 2 & 15 & n/a & n/a & n/a \\
\hline 2(trial 1) & 3 & 263 & 2 & 15 & 13 \\
\hline 2(trial 2) & 3 & 313 & 14 & 21 & 7 \\
\hline 2(trial 3) & 3 & 326 & 26 & 33 & 7 \\
\hline 3(trial 1) & 4 & 254 & 47 & 87 & 40 \\
\hline 3(trial 2) & 4 & 381 & 14 & 20 & 6 \\
\hline 4(trial 1) & n/a (retired) & 606 & 2 & n/a & n/a \\
\hline 4(trial 2) & n/a (retired) & 430 & 6 & 11 & 5 \\
\hline 5(trial 1) & n/a (p.a) & 840 & 10 & 80 & 70 \\
\hline 5(trial 2) & n/a (p.a) & 700 & 6 & n/a & n/a \\
\hline 6 & 5 & 716 & 23 & 41 & 18 \\
\hline
\end{tabular}

*Leak Rate Change is determined to find the true leak rate (baseline rate minus final closure rate), which can be used to give a value comparable to the first-leak rate.

\section{References}

1. Neumayer LA, Gawande AA, Wang J, et al. Proficiency of surgeons in inguinal hernia repair: effect of experience and age. Annals of surgery. Sep 2005;242(3):344-348; discussion 348-352.

2. Seymour NE, Gallagher AG, Roman SA, et al. Virtual reality training improves operating room performance: results of a randomized, double-blinded study. Annals of surgery. Oct 2002;236(4):458-463; discussion 463-454.

3. Selzer DJ, Dunnington GL. Surgical skills simulation: a shift in the conversation. Annals of surgery. Apr 2013;257(4):594-595.

4. Evgeniou E, Loizou P. Simulation-based surgical education. ANZ journal of surgery. Oct 222012. 
5. Sadideen $\mathrm{H}$, Hamaoui K, Saadeddin M, Kneebone R. Simulators and the simulation environment: getting the balance right in simulation-based surgical education. Int J Surg. 2012;10(9):458-462.

6. Pernar LI, Smink DS, Hicks G, Peyre SE. Residents can successfully teach basic surgical skills in the simulation center. Journal of surgical education. Sep-Oct 2012;69(5):617-622.

7. Popp AJ. Navigating the Strait of Magellan: mapping a new paradigm for neurosurgical residency training. Presidential address to the Society of Neurological Surgeons, May 7, 2007. Journal of neurosurgery. Oct 2008;109(4):576-582.

8. Faulkner ND, Finn MA, Anderson PA. Hydrostatic comparison of nonpenetrating titanium clips versus conventional suture for repair of spinal durotomies. Spine. Apr 20 2012;37(9):E535-539.

9. Takahashi $\mathrm{Y}$, Sato $\mathrm{T}$, Hyodo $\mathrm{H}$, et al. Incidental durotomy during lumbar spine surgery: risk factors and anatomic locations: clinical article. Journal of neurosurgery. Spine. Feb 2013;18(2):165-169.

10. Desai A, Ball PA, Bekelis K, et al. Surgery for lumbar degenerative spondylolisthesis in Spine Patient Outcomes Research Trial: does incidental durotomy affect outcome? Spine. Mar 1 2012;37(5):406-413.

11. Ruban D, O'Toole JE. Management of incidental durotomy in minimally invasive spine surgery. Neurosurgical focus. Oct 2011;31(4):E15.

12. Guerin $P$, El Fegoun $A B$, Obeid I, et al. Incidental durotomy during spine surgery: incidence, management and complications. A retrospective review. Injury. Apr 2012;43(4):397-401.

13. Tafazal SI, Sell PJ. Incidental durotomy in lumbar spine surgery: incidence and management. European spine journal : official publication of the European Spine Society, the European Spinal Deformity Society, and the European Section of the Cervical Spine Research Society. Apr 2005;14(3):287-290.

14. Cammisa FP, Jr., Girardi FP, Sangani PK, Parvataneni HK, Cadag S, Sandhu HS. Incidental durotomy in spine surgery. Spine. Oct 15 2000;25(20):2663-2667.

15. Goodkin R, Laska LL. Unintended "incidental" durotomy during surgery of the lumbar spine: medicolegal implications. Surgical neurology. Jan 1995;43(1):4-12; discussion 12-14.

16. Jones AA, Stambough JL, Balderston RA, Rothman RH, Booth RE, Jr. Long-term results of lumbar spine surgery complicated by unintended incidental durotomy. Spine. Apr 1989;14(4):443-446.

17. Stolke D, Sollmann WP, Seifert V. Intra- and postoperative complications in lumbar disc surgery. Spine. Jan 1989;14(1):56-59.

18. Khan $\mathrm{MH}$, Rihn J, Steele $\mathrm{G}$, et al. Postoperative management protocol for incidental dural tears during degenerative lumbar spine surgery: a review of 3,183 consecutive degenerative lumbar cases. Spine. Oct 15 2006;31(22):2609-2613.

Figure Legends

Figure 1: The standard durotomy repair model. An L3 laminectomy demonstrated a dural tube, held open by rostral and caudal foley pressure cuffs.

Figure 2: A $1.5 \mathrm{~cm}$ durotomy is made for practice closure.

Figure 3: The participant is then timed on their closure of a durotomy of a set length, which is then timed and compared over several trials. 
Figure 4: Dural repair model demonstrating dural closure, under fluid pressure. Performance is gauged by recording leak rates after each closure, measured in drips per second from the saline bag.

\section{Supplemental Video Legend}

Video 1. Summary video describing the various components of the cerebrospinal fluid leak simulator, assembly, operation, and general use in tandem with the didactic program. 